\title{
Unilateral impalpable testis — what does it take to change culture?
}

\author{
Abraham Cherian $^{1}$ \\ Received: 23 April 2021 / Revised: 23 April 2021 / Accepted: 2 May 2021 / Published online: 15 June 2021 \\ (C) Crown 2021
}

\section{Dear Editors,}

Often, when faced with evidence that demands a verdict and change as an integral part of our response, it is not enough for change to affect my own practice, but it must also have benefits on a much larger scale. This is very relevant for a publicly funded health service like ours in the United Kingdom.

Fundamentally, our natures are such that our response is brisk when there is a risk or an adverse event and is considered tardy otherwise. This is not progressive, good medical practice. So, what does it take to change culture? I believe this can be achieved on the basis of reasoning and risks. Notice I placed risk last. Delivering reason in one forum alone is still not enough and hence this letter. There are two important stakeholders in this scenario, namely the requester and the one who delivers that request. My focus is on the latter.

To place this introduction in context, my first step in reasoning was published in the British Medical Journal [1]. It highlighted the role of ultrasound in the detection of a unilateral impalpable testis in a child. The conclusion was that there is no role for any imaging in this scenario. Surgeons who explore the groin based on a scan have at times found it frustrating and, without the skill or infrastructure to aid laparoscopy, the child is then referred to another centre for anaesthetic and laparoscopy as a second procedure. This is wrong, put in the mildest form. Mixed with the reasoning of false positives, false negatives, parental anxiety, multiple anaesthetics, waste, harm and the only conclusive investigation being a diagnostic laparoscopy, this is a plea to all radiologists to refuse a request for ultrasound and, in fact, any imaging in the work-up for a unilateral impalpable testis in children. I hope we can together bring change and reduce health care costs [2].

\section{Declarations}

Conflicts of interest None

\section{References}

1. Cho A, Thomas J, Perera R, Cherian A (2019) Undescended testis. BMJ 364:1926

2. Tasian GE, Copp HL (2011) Diagnostic performance of ultrasound in nonpalpable cryptorchidism: a systematic review and meta-analysis. Pediatrics 127:119-128

Publisher's note Springer Nature remains neutral with regard to jurisdictional claims in published maps and institutional affiliations.

Abraham Cherian

cherian@doctors.org.uk

1 Department of Urology, Great Ormond Street Hospital for Children NHS Foundation Trust, London WC1N 3JH, UK 